\title{
FRUSTRAÇÃO E ÊXTASE: SOBRE A LITERATURA POLONESA EM TRADUÇÃO NA VISÃO DE UM TRADUTOR, POPULARIZADOR E POLONISTA
}

\author{
Frustration and Ecstasy: Translating, Promoting and Teaching Polish \\ Literature in Italy
}

\author{
Monika WOŹNIAK \\ Sapienza Università di Roma \\ Universidade de Roma "La Sapienza" \\ monika.wozniak@uniroma1.it \\ https://orcid.org/0000-0002-0137-5109
}

\begin{abstract}
RESUMO: Opresente ensaio propõe breve reflexão sobre os mecanismos de tradução de obras literárias das chamadas "pequenas culturas", tendo como exemplo a recepção da literatura polonesa na Itália. A análise diacrônica mostra como foi e permanece a falta de interesse dos editores em introduzir no mercado autores representantes de quase desconhecida cultura. Como resultado, a maioria das traduções do polonês foi fruto de iniciativas de pessoas comuns. Muitas traduções foram publicadas e ainda aparecem em pequenas editoras. A popularidade individual de determinados autores não resultou em despertar o interesse na literatura polonesa. No entanto, nas últimas décadas é possível vislumbrar mudanças, principalmente pelo surgimento de tradutores que traduzem diretamente do idioma polonês. $\mathrm{O}$ processo de globalização cultural e a circulação de informação fazem com que a Polônia deixe de ser percebida como um país distante e exótico e as obras de escritores poloneses, em especial os envolvidos em certos gêneros, atraiam com frequência a atenção dos editores italianos. Cada vez mais, a mídia possui um papel importante para promoção de certos escritores. Embora o aumento da presença da literatura polonesa no mercado editorial italiano seja quase exclusivamente limitado a obras contemporâneas, é positivo indicar o fato de que os tradutores desempenham um papel essencial e várias traduções surgem devido a paixão polonifílica deles. PALAVRAS-CHAVE: Literatura polonesa, Estudos Poloneses na Itália, traduções de literatura polonesa, poloneses ganhadores do Prêmio Nobel.
\end{abstract}

Tradução do resumo: Milena Woitovicz Cardoso 


\begin{abstract}
The essay proposes a brief reflection on the mechanisms of translating literary works from the so-called "minor cultures" on the example of the reception of Polish literature in Italy. The diachronic review shows that the main obstacle was and still is the lack of willingness of publishers to market authors representing an almost unknown culture, who cannot guarantee commercial profit. As a result, for a long time most of the translations from Polish were done by few and not necessarily talented enthusiasts of Polish culture. Many translations have been published and still appear in small publishing houses, which means that they can reach a limited audience. The popularity of individual authors such as Henryk Sienkiewicz once and Wisława Szymborska recently do not entail arousing interest in Polish literature as such. In recent decades, however, there have been some positive changes, above all the appearance of competent and talented translators translating directly from Polish. In the era of cultural globalization Poland has ceased to be perceived as a distant and exotic country, and the works of Polish writers, especially authors of crime novels or fantasy, are more likely to attract the attention of Italian publishers. Although the increase in the presence of Polish literature on the Italian publishing market is almost exclusively limited to contemporary works, it should be considered positive that the translators still play a key role in the selection and promotion of the Polish literature proposed to the Italian readers.
\end{abstract} KEY-WORDS: Polish literature, Polish studies in Italy, Polish literature translations, Polish Nobel Prize winners.

STRESZCZENIE: Esej proponuje krótką refleksję nad mechanizmami przekładu dzieł literackich pochodzących z tzw. „małych kultur” na przykładzie recepcji polskiej literatury we Włoszech. Przegląd diachroniczny pokazuje, że główną przeszkodą byłi wciąż pozostaje brak chęci wydawców do wprowadzania na rynek autorów reprezentujących niemal nieznaną kulturę, nie mogących zagwarantować komercyjnego zysku. W rezultacie przez długi czas większość przekładów z polskiego była owocem inicjatyw oddolnych, wychodzacych od nielicznych i niekoniecznie utalentowanych entuzjastów polskiej kultury. Wiele tłumaczeń ukazywało się i wciąż ukazuje w niedużych oficynach wydawniczych, co sprawia, że dotrzeć mogą do ograniczonego kręgu odbiorców. Popularność pojedynczych autorów-Henryka Sienkiewicza dawniej, Wisławy Szymborskiej dziś nie pociągnęła za sobą rozbudzenia zainteresowania literaturą polską jako taką. W ostatnich dziesięcioleciach dostrzec jednak można zmiany na lepsze, przede wszystkim pojawienie się kompetentnych i utalentowanych tłumaczy, przekładających bezpośrednio z języka polskiego. Procesy globalizacji kulturowej oraz szybszy i łatwiejszy obieg informacji sprawiają także, 
że Polska przestała być postrzegana jako kraj daleki i egzotyczny, a utwory polskich pisarzy, zwłaszcza uprawiających takie gatunki jak powieść kryminalna czy fantasy częściej przyciągają uwagę włoskich wydawców. Choć wzrost obecności polskiej literatury na włoskim rynku wydawniczym ogranicza się niemal wyłącznie do dzieł współczesnych, za pozytywny trzeba uznać fakt, że w procesie przyswajania polskich dzieł Włochom wciąż kluczową rolę odgrywają sami tłumacze i wiele przekładów powstaje w wyniku ich polonofilskiej pasji. SŁOWA KLUCZOWE: Literatura polska; Polonistyka włoska; Przekłady literatury polskiej, Polscy laureaci literackiej nagrody Nobla.

A reflexão sobre o mercado das obras literárias polonesas no exterior pode ser tanto motivo de frustração quanto de entusiasmo. A sensação de frustração é certamente mais evidente e compreensível. Numerosas são as barreiras e obstáculos enfrentados pelos popularizadores da literatura polonesa no exterior. Trata-se de uma literatura originária de uma cultura "pequena", "exótica", sobre a qual os destinatários no país alvo sabem pouco ou nada. É necessário primeiramente convencer os leitores a conhecê-la e convencer, acima de tudo, os editores que não enfrentam o risco de promover um produto possivelmente inviável economicamente, que não traga lucros. É relativamente mais fácil convencer as editoras de menor porte que visam atender a demanda de um nicho específico do mercado e que não possuem, entretanto, uma ampla rede de distribuição nem meios de promover os livros e, por conta disso, tais publicações alcançam um número limitado de leitores. Quando por sua vez acontece de algum romance polonês se tornar um bestseller internacional e despertar o interesse das grandes potências do mercado editorial, a qualidade da tradução acaba, frequentemente, sendo a última das preocupações dos editores, não sendo prática rara que eles nem sequer julguem necessário contratar um tradutor que conheça o idioma do original. Por vezes, encontrar tal pessoa não é tarefa fácil, porque afinal de contas de onde é que em um país, o qual não tem muito contato com a Polônia, podem surgir pessoas que dominem o idioma polonês o suficientemente bem para embarcar em tal empreitada literária? Onde e como podem ter aprendido esse idioma? Na era da internet e globalização, isso certamente se tornou mais fácil do que outrora, porém tal tarefa permanece sendo imensuravelmente mais difícil e improvável do que o aprendizado de algum dos idiomas de "grande peso".

Um exemplo de história "frustrante" da tradução da literatura polonesa, sem sombra de dúvida, é o de sua recepção na Itália. No século XIX, as poucas traduções do idioma polonês eram assunto de um limitado círculo de entusiastas da cultura polonesa, 
que, com árduo trabalho e determinação, aprendiam o idioma sem ter acesso a livros didáticos, dicionários e nem a professores, e caso não fossem capazes de dominar a língua em um grau suficiente para traduzirem do original, recorriam às traduções francesas ou russas. Em seguida as publicavam em periódicos arcando eles mesmos com os custos. Caso não tivessem dinheiro para isso, as traduções permaneciam como manuscritos ou eram lidas nos círculos de amigos (a respeito das traduções de literatura polonesa realizadas na Itália até a segunda metade do século consultar Bersano-Begey, 1949 e Preisner, 1949). Também é necessário admitir honestamente que a paixão pela literatura polonesa nem sempre vinha acompanhada de talento literário. Essas traduções atualmente possuem apenas valor histórico e não podemos as recomendar como material de leitura sem certo peso na consciência.

A primeira obra polonesa que se tornou verdadeiramente popular na Itália foi Quo vadis de Henryk Sienkiewicz. A história desse sucesso é emblemática. Quando Federigo Verdinois, fascinado pelo livro que por sua vez leu em russo e desse idioma o traduziu, propôs a sua impressão na imprensa, enfrentou inicialmente a recusa categórica por parte dos redatores, seguros de que um romance de um autor polonês desconhecido com a temática da antiguidade jamais poderia interessar o leitor italiano. Por fim, tendo de abrir mão de seus honorários, ele conseguiu publicar o livro Quo vadis em partes seriadas no Corriere di Napoli. O sucesso do livro foi avassalador, uma verdadeira febre sobre "Sienkiewicz" e "quovadismania" se alastrara pela Itália: na primeira década do século XX foram publicadas dezenas de edições de Quo vadis com centenas de milhares de exemplares e, em seguida, toda a obra de Sienkiewicz foi traduzida, incluindo até mesmo a sua parte menos interessante e de menor valor literário.

Do ponto de vista dos editores e da maioria dos tradutores, isso não era nada mais do que uma operação puramente comercial, logo se traduzia às pressas e de qualquer maneira, baseando-se nas traduções de outros idiomas ou plagiando as edições italianas anteriores. Em decorrência disso, a obra de Sienkiewicz fora praticamente rebaixada à categoria de literatura das massas ou até mesmo barata: nas décadas a seguir, Quo vadis estava presente no mercado italiano apenas na forma de adaptações desleixadas para o público juvenil. A fama de Sienkiewicz trouxe consigo o crescimento do interesse por outros escritores poloneses e pela literatura polonesa (WOŹNIAK; BIERANACKALICZNAR; RYBICKI, 2020).

Escritor polonês ou obra polonesa alguma fora capaz de atingir a mesma escala desse ambíguo sucesso de Sienkiewicz no século XX, apesar de que alguns autores tenham sido capazes de transpor a barreira da indiferença do mercado editorial 
italiano e conquistaram um círculo fiel de leitores. Um desses escritores foi Stanisław Lem, popular nos anos sessenta e setenta entre os fãs do gênero de ficção cientifica. Apesar de tudo, ele não ficou marcado no imaginário dos leitores como escritor polonês e seus contos e romances foram traduzidos majoritariamente a partir de traduções inglesas (isso diz respeito até mesmo às edições do começo do século XXI). Witold Gombrowicz também foi outro que despertou certo interesse, sua obra foi publicada na Itália a partir dos anos sessenta em traduções horrorosas, de qualidade lastimável e, já na virada do século, Andrzej Stasiuk também gozou de uma popularidade passageira. Já os amantes do gênero de reportagem sempre apreciaram e continuam apreciando Ryszard Kapuściński (PIACENTINI, 2011).

Nos últimos anos, as obras de ficção de Andrzej Sapkowski vêm se tornando muito populares. O caminho por ele percorrido até o leitor italiano não fora, entretanto menos ardiloso do que o percorrido por Sienkiewicz. Por muito tempo, os editores italianos não queriam sequer ouvir falar de publicar algum autor polonês desconhecido, que tivesse se esgueirado para dentro do espaço literário tradicionalmente reservado aos escritores anglo-saxões e anglo-americanos. Fora necessário o sucesso global do jogo Wiedźmin (The Witcher), para que as editoras italianas repensassem sua posição. Curiosa e também simbólica é o prefácio que os editores prepararam para as publicações seguintes dos livros de Sapkowski: pedem desculpas por - como fora pedido pelo autor - que as traduções fossem realizadas a partir do polonês e, em decorrência disso, nem sempre estão em harmonia total com a versão inglesa do jogo. A renomada série de televisão baseada no enredo dos livros realizada pela Netflix no final do ano de 2019 trouxe consigo o ressurgimento do interesse do público e da popularidade da saga The Witcher, que por sua vez já havia transposto a dimensão literária e se transformara em um fenômeno de cultura em massa transmidiática (VINCENZI, 2019). Por mais que o gênero da ficção científica conte com diversos representantes ilustres no solo polonês, como por exemplo, Andrzej Pilipiuk, Andrzej Ziemiański ou Jacek Dukaj, o entusiasmo dos leitores não foi o suficiente para despertar o interesse das editoras italianas por outros autores poloneses que se dedicam a esse gênero literário. Em contrapartida, os livros de investigação criminal poloneses vêm gozando de certa popularidade entre as editoras: alguns dos volumes da série histórica Noir de Marek Krajewski e alguns dos romances investigativos de Katarzyna Bonda, frequentemente divulgada como "Jo Nesbø da Europa Oriental”, já contam com publicações italianas.

É de se esperar que o status da literatura polonesa na Itália - pelo menos no que diz respeito a certos nomes - haverá de ser aprimorado após certos prêmios 
internacionais de alto prestigio, principalmente o prêmio Nobel: os escritores poloneses foram condecorados com ele em cinco ocasiões diferentes, sendo a última vez no ano de 2019. Na realidade, entretanto, a maioria dos laureados com o Nobel fora recepcionada pela crítica italiana sem grande empolgação, mas sim com irritação. Sienkiewicz, por mais que fosse muito popular na Itália, ao ser receber o prêmio fora julgado como "escritor para cozinheiras e donas de casa" e fora acusado de ter "roubado" o Nobel das mãos do poeta italiano Giosuè Carducci. Já Władysław Reymont (nobel em 1924) fora completamente desprezado. O Nobel para Czesław Miłosz, conhecido na Itália quase que somente como autor de Zniewolony umyst (Mente cativa), foi comentado dentro das categorias políticas, sugerindo assim que a decisão da comissão fora tomada guiando-se por motivos ideológicos e não pela qualidade da criação literária do escritor. É verdade que nos anos seguintes, Miłosz conquistou um maior reconhecimento por parte dos intelectuais italianos e que a maior parte de sua obra tenha sido traduzida, mas ele, porém, nunca chegou ao imaginário de um universo maior de leitores. Hoje em dia seu nome é familiar apenas para os polonistas italianos, já que seus livros há muito tempo sumiram das prateleiras das livrarias e podem ser encontrados apenas na internet (WOŹNIAK, 2014).

A crítica literária italiana reagiu de maneira igualmente cética sobre a nomeação de Wisława Szymborska (1996) ao Nobel, apesar de que em seu caso - sobre o qual já comentaremos - a lenda da Cinderela, excepcionalmente, tornou-se realidade, na qual o prêmio Nobel a fez rainha. O Nobel de Olga Tokarczuk (2018), por sua vez foi recepcionado mais positivamente, mesmo com ressalvas. O problema está no fato de que, até então, poucos dos seus livros foram traduzidos para o idioma italiano: nos últimos anos foram publicados apenas Prowadź swój pług przez kości zmartych (Sobre os ossos dos mortos, 2012, segunda edição em 2020) e em 2019, Bieguni (Os Vagantes). Alguns anos atrás, quando no festival literário em Mantui fora apresentado o "suspense investigativo ecológico" de Tokarczuk e recepcionado com entusiasmo pelos leitores, a escritora em vão tentara convencer os editores italianos para que tomassem a decisão de publicar seus demais livros, principalmente Księgi Jakubowe. Agora, quem sabe, a posição deles pode mudar, mas a questão é: será que, antes das demais traduções sejam realizadas, toda a atenção gerada pelo Nobel não terá já chegado ao fim?

A situação atual da literatura polonesa na Itália é evidentemente mais favorável do que a de cem anos atrás, seja pelo fato de que já existam tradutores que dominem o idioma polonês e que também sejam dotados de um certo talento literário. Nas últimas décadas vem surgindo também organizações que auxiliam na divulgação do livro polonês 
no exterior, principalmente o Instytut Książki (Instituto do Livro), que dá a possibilidade de bolsas para tradutores ou ajuda no financiamento de publicações de obras polonesas traduzidas. De tal possibilidade fazem uso cada vez mais editores, o que fez com que o número de traduções do polonês para o italiano crescesse cada vez mais.

Infelizmente, para muitas pequenas editoras, o financiamento em conjunto é simplesmente uma maneira de fazer um negócio não lá muito honesto: embolsam o dinheiro e lançam um livro com a tiragem mínima, de tal modo que o livro não tem chances de ter qualquer repercussão no mercado literário. Esse foi o caso que ocorreu recentemente com o Król Maciuś (Rei Mateusinho Primeiro) de Janusz Korczak. A primeira tradução dessa obra para o idioma italiano não chegou às livrarias e tampouco se fez visível nas plataformas de venda eletrônica. Exemplos não faltam: no decorrer das duas últimas décadas surgiram diversas traduções de valor, principalmente quando se trata de poesia (figuram entre elas poemas de Józef Czechowicz, Ryszard Krynicki, Bożena UmińskaKeff, Jan Twardowski) que são conhecidos apenas por uma pequena parcela de leitores já familiarizados com o meio. Por outro lado, as grandes editoras parecem continuar não dando a devida importância para esse pequeno detalhe que é a tradução direta do idioma no qual dada obra foi criada. A recente tradução de Cyberiada de Stanisław Lem foi realizada a partir da versão inglesa de autoria de Michael Kandel, detalhe sobre o qual não há informações nem na capa, nem no prefácio. Circulam também rumores de que o editor Feltrinelli encomendou a realização de uma nova versão de Ferdydurke de Witolad Gombrowicz para um escritor italiano que a assinará sem saber sequer uma palavra em polonês.

A imagem aqui traçada da situação da literatura polonesa traduzida pode parecer entristecedora e frustrante. Não há porque se iludir: as traduções do polonês, independentemente de seu real valor artístico, ainda se situam à margem do mercado internacional de livros, já os ocasionais sucessos de certos autores não acarretam em um despertar de interesse mais amplo pela literatura polonesa como tal. O lamento dos pesquisadores de que o quadro das traduções do idioma polonês na Itália é caótico, repleto de lacunas vazias e que não representa todo o legado literário polonês - tampouco no plano diacrônico, quanto no plano sincrônico, vem se repetindo ciclicamente através das décadas e ainda permanece atual (BERSANO-BEGEY, 1949; MARCHESANI, 1994; MARINELLI, 2002; PIACENTINI, 2011). Em compensação, com um pouco de boa vontade é possível observar aspectos positivos nessa situação. Primeiramente, significa ela que as traduções do polonês se encontram além das regras ditadas pelos mecanismos do mercado editorial, dentro dos quais, o que importa de fato é apenas a equação dos 
lucros e despesas. Diferentemente das literaturas dentro do mainstream, a posição do nicho da arte literária polonesa permite ao tradutor usufruir de uma maior autonomia tradutória, eleva-o para além da posição de um artista passivo que executa o trabalho a ele designado pelo editor. Nos dias de hoje, assim como um século atrás, a iniciativa de transposição de um dado livro ainda surge da parte do tradutor, ela tem início em um momento de epifania pessoal e de luta com os editores em nome de sua publicação.

Não é raro que, em tais circunstâncias, nasça e cresça uma amizade entre o autor e o tradutor, que assume o papel de embaixador e arauto do escritor em seu país, o seu defensor e cavaleiro de armadura brilhante. Essa atividade de divulgação e popularização sempre tem em si um elemento de imprevisibilidade, lembra um pouco um jogo de roleta: será que vai dar certo promover um novo autor ou será que não? As traduções que são como frutos de um longo e fatigante trabalho, muito frequentemente, passam pelo mercado despercebidas, sem gerar eco ou repercussão, começam e terminam sua vida nas prateleiras de bibliotecas nas quais ninguém as vê. Ocorre também, todavia, que a fidelidade, dedicação e fé do tradutor são recompensadas para além de todas suas expectativas.

Esse foi justamente o caso das traduções italianas de Wisława Szymborska realizadas por Pietro Marchesani. Marchesani, um polonista que faleceu no ano de 2011, era professor na Universidade de Gênova e tradutor literário. Ele havia se encantado pela poesia de Szymborska, quando ninguém na Itália ainda nem havia ouvido falar dela. Os primeiros tomos de traduções da futura nobel surgiram como livretos para amantes da literatura na editora de Vanni Scheiwiller, um admirador da cultura polonesa e amigo de Marchesani. Esses livros foram distribuídos para um círculo específico de leitores já familiarizados e interessados pelo assunto. Após a premiação da autora em Estocolmo, a editora Adelphi tomou a decisão de publicar sua poesia, inicialmente nada indicava que isso levaria a algo maior do que o reconhecimento devido à laureada de tal condecoração de prestigio, afinal de contas esse fora o caso de Czesław Miłosz.

Já neste meio tempo, os poemas de Szymborska “vingaram” em solo italiano. Sua mensagem de caráter universal cativou até mesmo os leitores até então não interessados pela cultura polonesa. $\mathrm{O}$ interesse pela sua obra cresceu gradualmente na primeira década do novo século e as numerosas visitas da poeta à Itália e encontros autorais lá organizados resultaram em um aumento no número de seus admiradores (MARINELLI, 2016). Em seguida, no ano de 2012, um milagre aconteceu: no programa televisivo Che tempo che $f a$, quatro dias após o falecimento da escritora, o renomado escritor italiano Roberto Saviano, autor da famosa Gomorra declamou Szymborska e se pronunciou com grande 
reconhecimento sobre a escritora. No dia seguinte uma multidão de italianos esperava às portas das livrarias: em menos de uma semana se esgotaram as dezenas de centenas de exemplares de Poezje zebrane - um recorde de vendas que até então não havia sido quebrado por nenhum outro poeta moderno, tanto italiano quanto estrangeiro. As citações de Szymborska começaram a aparecer por toda parte: nos livros escolares, nos jornais, nas paredes de museu e até mesmo em manuais de negócios. O sucesso de Szymborksa foi um momento triunfal para a literatura polonesa, mas também para Pietro Marchesani, que fora o primeiro na Itália a descobrir a obra de Szymborska e que em seguida se tornou seu único e oficial tradutor italiano até o momento de sua morte (infelizmente faleceu sem ter presenciado o momento quando a popularidade de Szymborska fora além dos limites da literatura, se tornando um fenômeno da cultura de massa).

É possível que tal aventura espere por Barbara Delfino que atualmente é a embaixadora italiana da obra de Olga Tokarczuk. Delfino, diferentemente de Raffaella Belletti, uma tradutora profissional do inglês, russo, tcheco e polonês que traduzira para o italiano sem grande desenvoltura e real compreensão algumas das primeiras obras de Tokarczuk, tem seu lugar dentro da nobre galeria histórica dos "tradutores com uma missão". Apaixonada pelo idioma e cultura polonesa, há muito tempo desejava medir suas forças com a prosa de Tokarczuk: a tradução de Bieguni foi para ela a realização de um sonho e oportunidade de conhecer a autora com a qual depois desenvolveu uma autêntica e sincera amizade. Delfino se tornou mais do que apenas uma tradutora, uma vez que também é autora de artigos sobre a escritora, popularizadora e parceira de diálogos durante encontros autorais e entrevistas realizadas na Itália. Barbara Delfino também foi agraciada com o reconhecimento merecido pela sua paixão missionária: uma parte da fama do prêmio Nobel chegou também a ela. Do mesmo modo que há mais de cem anos, Federigo Verdinois, após ter traduzido Quo Vadis se tornou uma figura reconhecida e respeitada no meio literário. Ele se tornou um tradutor cuja opinião os editores tinham de levar em consideração. Assim, Barbara Delfino garantiu para si o papel de autoridade nas questões de tradução da literatura polonesa.

E aqui uma última reflexão, expressa do ponto de vista de uma polonista que trabalha no exterior. Minhas experiências me sugerem que o interesse pela literatura polonesa raramente - propriamente nunca - é o motivo pelo qual se escolhe o polonês como objeto de estudo na universidade. O que decide é o acaso, as raízes polonesas, contatos no trabalho - assim como - ligações sentimentais, um puro cálculo (vale a pena estudar um idioma incomum de um país membro da União Europeia). Como resposta para a pergunta sobre os escritores poloneses, os estudantes do primeiro ano (quem sabe com 
a exceção daqueles que são descendentes de emigrantes poloneses), por via de regra, não são capazes de citar nome algum; por mais que já tenham tido contato com Sapkowski ou Szymborska, de modo geral, eles não têm consciência de que se tratam de escritores poloneses. Logo os professores têm não somente a tarefa de ensinar sobre a literatura polonesa, mas acima de tudo de aproximá-la aos estudantes, de fomentar neles essa santa paixão, que fará deles os embaixadores da cultura polonesa no exterior.

A realização desse objetivo nem sempre é tarefa fácil, mas cada sucesso conquistado traz consigo uma enorme satisfação e sensação de missão cumprida. A tradição de ensino do idioma polonês nas universidades italianas possui uma longa história. No ano de 2019, foi comemorado o aniversário de noventa anos da fundação do curso de idioma e literatura polonesa na Universidade de Roma "La Sapienza" e no ano seguinte a mesma data comemorativa foi celebrada pela Universidade de Turim. Já o curso de letras polonês na Universidade de Nápoles foi fundado mais recentemente no ano de 1942. Na segunda metade do século XX, começaram a surgir mais instituições de ensino da língua e literatura polonesa. Nos dias de hoje existem dezenas delas, o que pode gerar a impressão de abundância, mas em sua grande maioria trata-se dos assim chamados cursos "monodocentes", nos quais um professor é responsável pelo processo de ensino em sua totalidade. A atividade docente em tais condições configura um verdadeiro desafio e os polonistas italianos merecem todo o nosso reconhecimento e apreciação por sua energia e devoção. É graças ao desenvolvimento do ensino de polonês no nível acadêmico que, durante as últimas décadas, surgiram na Itália tradutores da literatura polonesa de peso, conhecedores não somente das obras, mas também do contexto literário que são capazes de interpretar devidamente sua poética e mensagem. Muitos tradutores justamente unem a prática tradutória com o ensino acadêmico, assim como o aqui anteriormente citado Pietro Marchesani, tradutor de Wisława Szymborska e Miłosz, ou Luigi Marinelli e Monika Woźniak da Universidade de Roma "La Sapienza", ou, ainda, Andrea Ceccherelli de Bologna: na prática todo polonista italiano que atua nas universidades conta com uma empreitada tradutória em seu histórico. No resultado final, ainda que nem todas as traduções do idioma polonês publicadas na Itália sejam de boa qualidade e realizadas diretamente do original, existe um número cada vez maior de bons tradutores e de excelentes tradutores.

É possível que o ponto sensível, a maior falha da literatura polonesa traduzida para o italiano seja o fato, de que tanto o interesse dos tradutores, quanto dos editores se concentre praticamente nas obras da modernidade: quase ninguém traduz novamente os clássicos (uma exceção digna de nota foi a tradução não muito bem sucedida de Pan 
Tadeusz de Adam Mickiewicz, publicada em 2018, de autoria da tradutora de mérito Silvana de Fanti).

As traduções antigas, ainda que disponíveis (quando por exemplo se renova Quo Vadis, continuam sendo utilizadas traduções do início do século XX de qualidade que deixa a desejar) não podemos, sem remorsos, recomendar aos estudantes como material de leitura, uma vez que podem surtir o efeito contrário ao desejado e desanimá-los efetivamente da leitura de obras polonesas. Uma parcela das obras literárias polonesas de maior significância, como por exemplo, Nad Niemnem de Eliza Orzeszkowa ou Noce $i$ $d n i$ de autoria de Maria Dąbrowska permanecem sem traduções, ainda que parciais, até os dias de hoje. Significa isso que a afirmação de que "Słowacki foi um grande poeta", para aqui citar o professor Bladaczka ${ }^{1}$, precisa ser tomada cegamente por verdade, já que vão passar alguns anos até que os estudantes aprendam e dominem o idioma suficientemente bem para poder lê-lo no original. Mas quem é que sabe se essa barreira não pode servir como um novo, empolgante desafio e impulso para medir forças em uma tarefa mais árdua do que o de costume?

Isso foi o que aconteceu no curso de letras polonês em Roma, de onde surge uma nova tradução de Dziady de Adam Mickiewicz preparada por uma doutoranda de grandes aspirações. Agora se ela vai encontrar depois uma editora e leitores, isso já é obviamente uma outra história...

Tradução: Matheus Moreira Pena

\footnotetext{
${ }^{1}$ Referência ao romance "Ferdydurke" de Witold Gombrowicz (Nota da redação). 


\section{REFERÊNCIAS:}

BERSANO-BEGEY, Maria; BERSANO-BEGEY, Marina . La Polonia in Italia. Saggio bibliografico 1799-1948. Torino: Rosenberg e Sellier, 1949.

CECCHERELLI, Andrea. Non solo Szymborska. Venticinque anni di poesia polacca tradotta in italiano (1989-2013). Europa Orientalis, 34, 2015. p. $379-396$.

MARCHESANI, Pietro. La narrativa polacca in Italia negli anni 1945-1990. In: MARCHESANI, P. (ed.). La letteratura polacca contemporanea in Italia. Itinerari di una presenza. Roma: La Fenice Edizioni, 1994. p. 15-34.

MARINELLI, Luigi. Sulla letteratura polacca in Italia negli ultimi dieci anni: canone, anticanone, "bigos". In: COSENTINO, A. (ed.), Cinque letterature oggi. Russa, polacca, serba, ceca, ungherese. Udine: Forum, 2002. p. 133-145.

MARINELLI, Luigi. La fiera dei miracoli ovvero Wisława Szymborska (e lo szymborskismo) in Italia. In: CECCHERELLI, A.; MARINELLI, L.; PIACENTINI, M. Szymborska. Un alfabeto del mondo. Roma: Donzelli, 2016. p. 243-257.

PIACENTINI, Marcello. Per conoscere la Polonia in Italia: rassegna bibliografica minima. Quaderni del Premio Letterario Giuseppe Acerbi, 12, 2011. p.147-151.

PREISNER, Walerian. Stosunki literackie polsko - włoskie w latach 1800 - 1939. W świetle bibliografii. Toruń: Toruńskie Towarzystwo Naukowe, 1949.

VINCENZI, Davide. The Witcher: da romanzo sconosciuto a fenomeno di costume. Cultura pop, 19 dez. 2019. Disponível em: <https://www.tomshw.it/culturapop/thewitcher-da-romanzo-sconosciuto-a-fenomeno-di-costume/>. Acesso em 20 ago. 2020.

WOŹNIAK, Monika. Włoskie parateksty Czesława Miłosza. In: BILCZEWSKI, T.; MARINELLI, L.; WOŹNIAK, M. (eds.) Rodzinny świat Czesława Miłosza. Kraków: Wydawnictwo Uniwersytetu Jagiellońskiego, 2014. p. 227-234.

WOŹNIAK, Monika; BIERNACKA-LICZNAR, Katarzyna; RYBICKI, Jan. 120 lat recepcji „Quo vadis” Henryka Sienkiewicza we Włoszech. Warszawa: DiG, 2020.

ZIELIŃSKI, Andrzej. Presenza polacca nell'Italia dell'entre-deux-guerres. Milano: Franco Angeli, 2018. 